\title{
Computer modelling of the effect of embodied energy on energetic effectiveness of biodiesel production
}

\author{
Olga Orynycz, ${ }^{1, *}$, and Andrzej Wasiak $^{1}$ \\ ${ }^{1}$ Bialystok University of Technology, Dept. of Production Management, Wiejska 45A, 15-351 Bialystok, Poland
}

\begin{abstract}
The effect of embodied energy on energetic effectiveness of biodiesel production is studied. Embodied energy, i.e. energy consumed for production of a technical device, is gradually consumed during the life time of that device. The amount of embodied energy consumed during individual agricultural operation affects the energetic effectiveness of that operation, as well as that for the whole production process. The embodied energy in agriculture is associated with the use of machinery, transportation means, fertilizes, etc. The paper estimates the effect of embodied energy in the rapeseed biodiesel production basing on computer modelling.
\end{abstract}

\section{Introduction}

The growing demand on energy causes the growth of the interest in use of the various forms of renewable energy. The growing prices of energy inflicts needs for careful estimation of the costs of energy consumed in agricultural production, as well as of taking care of energetic efficiency of the production technology and equipment used [1]. The rational economy of energy becomes one of fundamental requirements in present agriculture.

So far, the oil is one of main carriers of energy used in farms. The partial replacement of mineral fuels by energy derived from agricultural crops may offer the additional contribution to the agricultural Energy balance [2]. The number of articles describing the tillage technology of energetic plants exists in the literature [35], and also concerning the conversion of crops into biofuels $[6,7]$. Considerable differences are visible in the number and the ways of carrying out the agrotechnical operations that should provide the best properties of soil and the highest yield of the crops. The Energy consumption is one of important elements affecting profitability of the tasks.

Mathematical model of agricultural processes, including all important factors affecting the energetic efficiency of plantation, may be an important tool for production planning, and for selection of machinery and other production means assuring optimisation of the production system.

The holistic, multidisciplinary system approach is frequently used for analysis and description of agricultural production [8-10], structural modelling represented in the present paper, may also give important insight into reasons of the observed phenomena.

Energetic efficiency of biofuel production system is dependent upon many factors including production technology, machines and other production means used, but also climatic or soil conditions etc.

There are three main factors affecting the energetic effectiveness of an energetic plantation: one is the yield and calorific value of the crop, while the other -direct fuel consumption during agrotechnical and transport operation, and the third factor is embodied energy i.e. the Energy contained in the technical means [11] used in all operations involved. Mechanisation and intensification of agricultural production is coupled with the growth of directly consumed energy [12], as well as of this indirect contribution of embodied Energy. Embodied Energy is defined as Energy consumed in order to produce a specified technical object, and Energy consumed for repairs and maintenance of that technical object during its whole lifetime. This means that the term "embodied Energy" is dependent not only upon conditions of production of particular technical device, but also on the style and culture of exploitation of this device.

The complexity of this problems causes needs the studies and analyses of these factors. The present paper gives preliminary estimates of the effects of embodied Energy on the energetic effectiveness of a plantation in relations to the contribution of direct Energy consumption in several tillage technologies.

In the present paper the following tillage technologies are considered: ploughing, which is the most frequently used, cut-off method, and finally without ploughing - both of which are less popular.

\section{The technical aspects of energetic efficiency}

Efficiency of the plantation can be expressed as the ratio of total produced energy to the quantity of energetic expenditures being used. The coefficient EROEI (Energy

* Corresponding author: o.orynycz@pb.edu.p1 
Returned on Energy Invested) is used to the evaluation of fuels as the carriers of Energy [13-15].

The energy consumption in production processes is related to the calorific value and the amount of the fuel consumed. This consumption is mainly associated to the agrotechnical operations, as well as transport of goods. An additional expense is so called embodied Energy that is contained in the technical means. Embodied energy (the quantity of energy, used to produce some goods equivalent to the notion of energy[16-18]) is contained in the technical means (e.g. the chemicals for protection of plants, devices, fertilizers), and depends on the kind of equipment and other technical means used. The amount of embodied Energy that is assigned to particular process can be estimated as the fraction of embodied Energy consumed in that process related to that total embodied Energy, $V_{k}$, of particular object. For example: if a tractor is expected to work for 10 years, and in particular process is used for one month than the fraction, $V_{k}$, is proportional to the ratio 1 month to 120 months.

The energetic efficiency can be expressed as:

$$
\varepsilon=V_{\text {alt }} / V_{\text {use }}
$$

The value $\varepsilon=1$ occurs in the situation, when contributions of energy consumed in technological processes are equal to the produced energy, coefficient $\varepsilon<1$ show energetic losses. Only the results with $\varepsilon>1$ are useful because they correspond to higher energy content in biofuel than is consumed during production. Differences in the values of energetic efficiency depend on the quantity of energetic expenditures, as well as on embodied energy corresponding to the energy consumed during production of material goods (tools, etc.) being used.

The total quantity of energy contained in the biofuel is expressed as:

$$
V_{\text {alt }}=P \times B_{\text {yield }}\left(y_{f}, y_{w}, y_{c p}\right) \times \alpha \times \Sigma_{k=1}^{n} \delta_{k} \times Q_{\text {alt }}
$$

where:

$P$ - the size of the plantation,

$B_{\text {yield }}\left(y_{f}, y_{w}, y_{c p}\right)$ - the size of the crop (dependent from doses: $y_{f}$ - the fertilizers, $y_{w}$ - the water, $y_{c p}$ - the means of the protection of plants),

$\alpha$ - the general mass of the biofuel obtained from the plantation,

$\delta_{k}$ - the mass fraction of the $k$-th species of the biofuel,

$Q_{\text {alt }}$ - the energetic value of $k$-th species of the biofuel.

The contribution of factors influencing crops yield makes up only certain part of embodied energy consumed in particular operation. $V_{k}$ denotes the quantity of embodied energy, which is used during the work on the unit of the plantation area, or on the individual distance driven with the given means of transportation. The amount of energy consumed on field during the agrotechnical operations can be written as:

$$
V_{u s e}=Q_{c o m} \times P \times \Sigma_{i=1}^{m}\left[\frac{l_{i}}{u_{i}}\right]+\sum_{i=1}^{m} \Sigma_{k=1}^{K} \alpha_{i k} \times V_{k}
$$

where:

$l_{i}$ - the consumption of fuel on the unit of the distance driven,

$u_{i}$ - the width of worked strip of land in $i$-th operation,

$Q_{\text {com }}$ - the calorific value of the fuel used in agrotechnical works,

$m$ - the number of agrotechnical operations,

$\alpha_{i_{k}}-$ the fraction of "built-in" energy contained in $k$-th technical device, used in $i$-th operation.

The parameter $l / u$ characterises the equipment used and can be defined through the proper selection of equipment in any particular case.

Energetic efficiency derived on the basis of above equations can be expressed as:

$$
\begin{aligned}
& \varepsilon=\frac{V_{\text {alt }}}{V_{u s e}} \\
& =\frac{P \times B_{\text {yield }}\left(y_{f}, y_{w}, y_{c p}\right) \times \alpha \times \sum_{k=1}^{n} \times \delta_{k} \times Q_{\text {alt }}}{Q_{\text {com }} \times P \times \sum_{i=1}^{m}\left[\frac{l_{i}}{u_{i}}\right]+\sum_{i=1}^{m} \sum_{k=1}^{K} \times \alpha_{i k} \times V_{k}}
\end{aligned}
$$

It is visible, that energy contained in the production means depends on the technology, on the kind of equipment used in agrotechnical and other means applied in tillage. It is seen that the expression defining the contribution of embodied energy built-in the technical means, reduces energetic efficiency.

The effects of technological choices on the efficiency of the energetic plantation will be analysed below basing on calculations using the data from chosen agricultural farms.

Data obtained from chosen agricultural farms illustrate practical utilisation of several tillage methods and bring the attention to the use of the variants of technologies showing various requirements with respect to Energy consumption. The comparison of the main methods of tillage of winter rape is presented in Table 1 showing the combination of agrotechnical operations involved in the particular method.

Specification of production variants and the time of work for each variant, as well as consumption of diesel fuel during those operations is given in Table 2.

The presented variants starting from classical approach, go into direction of contemporary agriculture tending to decrease the number of operations, and consequently to decrease the energy consumption. 
Table 1. Agrotechnical operations used in various methods of tillage in winter rape production.

\begin{tabular}{|c|c|c|}
\hline $\begin{array}{c}\text { Method } \\
\text { ploughing }\end{array}$ & Method cut-off & $\begin{array}{l}\text { Method without } \\
\text { ploughing }\end{array}$ \\
\hline $\begin{array}{l}\text { - Forecrop (soil } \\
\text { preparation) } \\
\text { - Disking (turfed } \\
\text { soil) } \\
\text { - First ploughing } \\
\text { - Harrowing } \\
\text { - Row-sowing } \\
\text { (18-22 cm) } \\
\text { - Rolling } \\
\text { - Sowing } \\
\text { - Nurturing } \\
\text { (spraying, } \\
\text { fertilizers) }\end{array}$ & $\begin{array}{l}\text { - Forecrop } \\
\text { (leaving post- } \\
\text { harvest remnants) } \\
\text { - Rototilling or } \\
\text { cultivating (8-10 } \\
\mathrm{cm} \text { ) } \\
\text { - Harrowing } \\
\text { - Row-sowing } \\
\text {-Nurturing } \\
\text { (spraying, } \\
\text { fertilizers) }\end{array}$ & $\begin{array}{l}\text { - Forecrop } \\
\text { - without } \\
\text { surface } \\
\text { treatment } \\
\text { - row-sowing } \\
\text { - nurturing } \\
\text { (spraying, } \\
\text { fertilizers) }\end{array}$ \\
\hline
\end{tabular}

Table 2. Working time and fuel consumption for tillage of 1 ha rapeseed plantation with the use of various technologies.

\begin{tabular}{|c|c|c|c|c|}
\hline 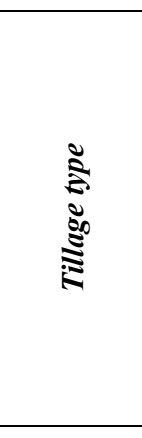 & 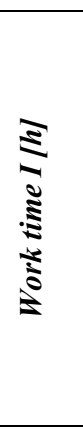 & 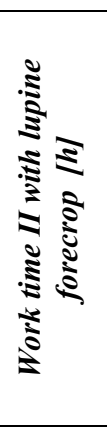 & 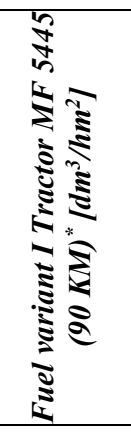 & 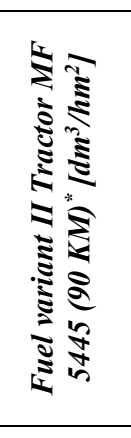 \\
\hline ploughing & 9 & 16 & 72 & 128 \\
\hline cut-off & 7 & 14 & 56 & 112 \\
\hline \multirow[t]{2}{*}{$\begin{array}{r}\text { without } \\
\text { ploughing }\end{array}$} & 6 & 13 & 48 & 104 \\
\hline & $\begin{array}{l}\Xi \\
\Xi \\
\vdots \\
\vdots \\
\vdots \\
\vdots \\
\Xi\end{array}$ & 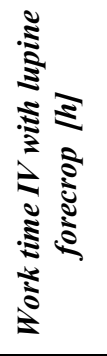 & 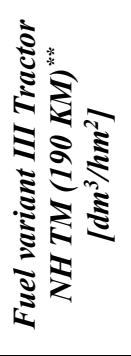 & 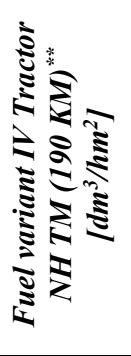 \\
\hline ploughing & 7 & 11 & 105 & 165 \\
\hline cut-off & 5 & 9 & 75 & 135 \\
\hline $\begin{array}{r}\text { without } \\
\text { ploughing }\end{array}$ & 4 & 8 & 60 & 120 \\
\hline
\end{tabular}

* specific fuel consumption $8 \mathrm{dm}^{3} / \mathrm{h}$

** specific fuel consumption $15 \mathrm{dm}^{3} / \mathrm{h}$

Each of these methods requires the use of diesel fuel. Energetic efficiency is dependent on the choice of tillage technology determined by the fuel consumption. The results of computations are shown in Table $3 \mathrm{a}$ and Table 3b. Some of the differences between variants result of specific fuel consumption, the other depend on the kind the applied forecrop whose tillage absorbs from several to tens litres of the fuel per hectare. The evaluation of energy expenditures in various technologies has to consider composition of operations being realized in those technologies. In present work it was accepted that the fuel consumption was directly proportional to the time of work, and the calorific value of the fuel value is equal to $36\left[\mathrm{MJ} / \mathrm{dm}^{3}\right]$.

Table 3a. The Energy consumption in two variants of tillage applied in rapeseed plantations.

\begin{tabular}{|c|c|c|c|c|}
\hline 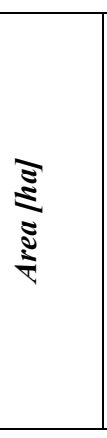 & 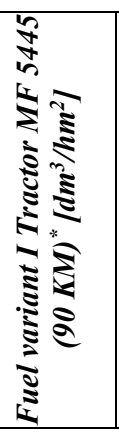 & 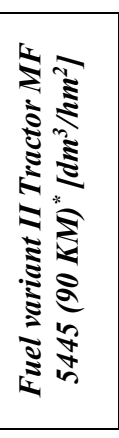 & 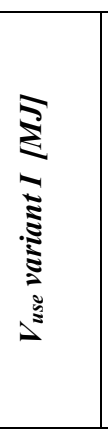 & 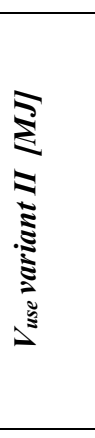 \\
\hline \multicolumn{5}{|c|}{ Ploughing } \\
\hline 2 & 72 & 128 & 5184 & 9216 \\
\hline 10 & 72 & 128 & 25920 & 46080 \\
\hline 20 & 72 & 128 & 51840 & 92160 \\
\hline \multicolumn{5}{|c|}{ Cut-off } \\
\hline 2 & 56 & 112 & 4032 & 8064 \\
\hline 10 & 56 & 112 & 20160 & 40320 \\
\hline 20 & 56 & 112 & 40320 & 80640 \\
\hline \multicolumn{5}{|c|}{ Without ploughing } \\
\hline 2 & 48 & 104 & 3456 & 7488 \\
\hline 10 & 48 & 104 & 17280 & 37440 \\
\hline 20 & 48 & 104 & 34560 & 74880 \\
\hline
\end{tabular}

Further task requires estimation of the amount of energy gained from the plantation. In the case of rape plantation, the biomass harvested is not a direct source of Energy; it must be converted in industrial processes.

The amount of energy, $V_{a l t}$, received after the conversion of the biomass can be assumed to be equal to the average value that is obtained from industry

The literature concerning methods of tillage, types of equipment being used, as well as means of plants protection, provide quite divergent data on the biomass yield from a plantation. Unification of the task requires certain assumptions. Basing on the data from selected plantations the rapeseed grain yield was assumed to be on the level 3,5 $\mathrm{Mg}$ per hectare (which corresponds to biodiesel yield equal to $1330 \mathrm{dm}^{3} / \mathrm{ha}$ ). As an example: from 20 ha plantation one can get $26600 \mathrm{dm}^{3}$ of biodiesel fuel. Considering the calorific value of biodiesel equal to $34.59 \mathrm{MJ} / \mathrm{dm}^{3}$ the yield of energy from 20 ha of the plantation amounts to $920094 \mathrm{MJ}$.

The values of the partial energetic efficiency for agricultural part of production system [19] i.e. the ratio of the amount of energy contained in biofuel to the energy inputs needed for the variants of tillage technology, are shown in Table 4. 
Table 3b. The Energy consumption in two next variants of tillage applied in rapeseed plantations.

\begin{tabular}{|c|c|c|c|c|}
\hline 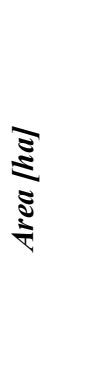 & 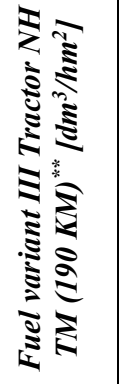 & 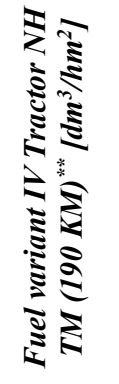 & 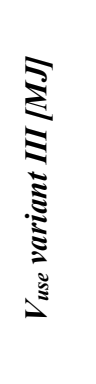 & 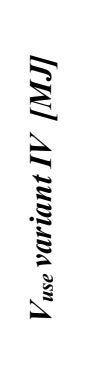 \\
\hline \multicolumn{5}{|c|}{ Ploughing } \\
\hline 2 & 105 & 165 & 7560 & 11880 \\
\hline 10 & 105 & 165 & 37800 & 59400 \\
\hline 20 & 105 & 165 & 75600 & 118800 \\
\hline \multicolumn{5}{|c|}{ Cut-off } \\
\hline 2 & 75 & 135 & 5400 & 9720 \\
\hline 10 & 75 & 135 & 27000 & 48600 \\
\hline 20 & 75 & 135 & 54000 & 97200 \\
\hline \multicolumn{5}{|c|}{ Without ploughing } \\
\hline 2 & 60 & 120 & 4320 & 8640 \\
\hline 10 & 60 & 120 & 21600 & 43200 \\
\hline 20 & 60 & 120 & 43200 & 86400 \\
\hline
\end{tabular}

It can be seen that those values differ only slightly in dependence on the method of tillage. The results presented in Table 4 consider only agrotechnical operations, and do not consider energy consumed in transportation outside the field.

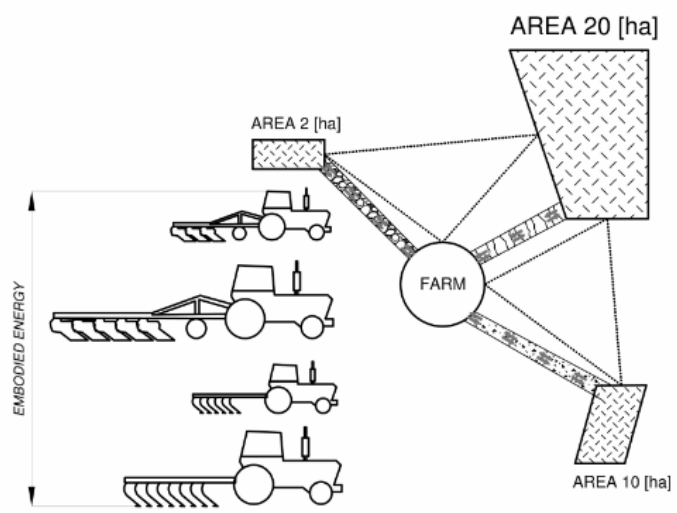

Fig. 1. Energy embodied in technical means used in agrotechnical operations.

Estimation of embedded energy is a difficult task because it should be performed separately for every type of machine and every kind of technical devices, and also fertilizers, crop protection means, etc. used in agrotechnical operations. The symbolic picture of technical objects contributing to the consumption of embodied energy in agricultural farm is given in Fig. 1.
Table 4. Partial energetic efficiency for chosen methods of the rape tillage.

\begin{tabular}{|c|c|c|c|c|}
\hline $\begin{array}{l}\text { Area } \\
\text { [ha] }\end{array}$ & $\begin{array}{c}V_{\text {alt }} V_{\text {use }} \\
\text { I [MJ] }\end{array}$ & $\begin{array}{l}V_{\text {alt }} / V_{\text {use }} \\
\text { II [MJ] }\end{array}$ & $\begin{array}{l}V_{\text {alt }} / V_{\text {use }} \\
\text { III [MJ] }\end{array}$ & $\begin{array}{l}V_{\text {alt }} / V_{\text {use }} \\
I V[M J]\end{array}$ \\
\hline \multicolumn{5}{|c|}{ Ploughing } \\
\hline 2 & 17.75 & 9.98 & 12.17 & 7.74 \\
\hline 10 & 17.75 & 9.98 & 12.17 & 7.74 \\
\hline 20 & 17.75 & 9.98 & 12.17 & 7.74 \\
\hline \multicolumn{5}{|c|}{ Cut-off } \\
\hline 2 & 22.82 & 11.41 & 17.04 & 9.47 \\
\hline 10 & 22.82 & 11.41 & 17.04 & 9.47 \\
\hline 20 & 22.82 & 11.41 & 17.04 & 9.47 \\
\hline \multicolumn{5}{|c|}{ Without ploughing } \\
\hline 2 & 26.62 & 12.29 & 21.30 & 10.65 \\
\hline 10 & 26.62 & 12.29 & 21.30 & 10.65 \\
\hline 20 & 26.62 & 12.29 & 21.30 & 10.65 \\
\hline
\end{tabular}

According to Börjesson [20] contribution of embodied Energy into energetic efficiency of agriculture is dependent upon types of machines used in farms, and on the use of other production means, like various equipment, fertilizers, insecticides, herbicides, etc. The contribution of embodied Energy of long lasting machines is computed considering an average annual share of Energy used for production of that machine plus estimated Energy that will be used for repairs, as prognosed for the whole life time. The other paper [21] estimates approximate contribution of embodied Energy in 50 ha agricultural farm as equal to $25 \mathrm{GJ} /$ year. Basing on those data, the influences of embodied Energy contribution on the energetic efficiency of, discussed above, variants of tillage technology are presented in Table 5.

It can be seen that considering embodied energy causes a decrease of energetic efficiency in the all cases of technological variants studied. The observed decrease of energetic efficiency is around $7 \%$ to $24 \%$, depending on the initial value of efficiency (Table 4).

It can be expected that the bigger are machines being used the higher will be the contribution of embodied energy, and consequently the lower global energetic efficiency of the production system. The reliability of the equipment, in turn, causing a decrease of expected defects, and consequently reduction of the needs of repairs will cause an increase of energetic effectiveness. It has to be considered that in the present calculations, energy embedded, $V_{k}$, in technical equipment used in transportation outside of the fields is not considered. If this factor was considered, the further decrease of energetic efficiency would be observed. 
Table 5. Partial energetic efficiency considering contribution of embodied energy for chosen methods of the rape tillage.

\begin{tabular}{|c|c|c|c|c|}
\hline $\begin{array}{c}\text { Area } \\
\text { [ha] }\end{array}$ & $\begin{array}{c}V_{\text {alt }} / V_{\text {use }} I \\
{[M J]}\end{array}$ & $\begin{array}{c}V_{\text {alt }} / V_{\text {use }} I I \\
{[\text { [MJ] }}\end{array}$ & $\begin{array}{l}V_{\text {alt }} / V_{\text {use }} \\
\text { III [MJ] }\end{array}$ & $\begin{array}{l}V_{\text {alt }} \text { V Vuse } \\
I V[M J]\end{array}$ \\
\hline \multicolumn{5}{|c|}{ Ploughing } \\
\hline 2 & 14.88 & 9.01 & 10.75 & 7.14 \\
\hline 10 & 14.88 & 9.01 & 10.75 & 7.14 \\
\hline 20 & 14.88 & 9.01 & 10.75 & 7.14 \\
\hline \multicolumn{5}{|c|}{ Cut-off } \\
\hline 2 & 18.28 & 10.15 & 14.38 & 8.58 \\
\hline 10 & 18.28 & 10.15 & 14.38 & 8.58 \\
\hline 20 & 18.28 & 10.15 & 14.38 & 8.58 \\
\hline \multicolumn{5}{|c|}{ Without ploughing } \\
\hline 2 & 20.65 & 10.84 & 17.29 & 9.54 \\
\hline 10 & 20.65 & 10.84 & 17.29 & 9.54 \\
\hline 20 & 20.65 & 10.84 & 17.29 & 9.54 \\
\hline
\end{tabular}

\section{Conclusions}

Presented above preliminary computations of the effects of the contribution of energy embodied in technical objects used in agrotechnical operations carried out in rapeseed plantations, dedicated to biofuel production, indicate that the expected effect is a decrease of the total energetic efficiency of the agricultural production system. The computed decrease of energetic efficiency is not very high and is dependent upon initial value of partial coefficient of energetic efficiency.

In many other cases, the effects will also depend upon the size of machines, they expected life time, and their reliability. Consequently, the better equipment is used the higher energetic efficiency is obtained

Since the simplified procedure of embodied energy estimation was used, a quite large error may be expected in presented results. One of the important reasons of using such procedure is lack of adequate data, and reliable calculation procedures.

All those factors indicate the need for further research in both directions, i.e. accumulation of data on energy consumption in production of specific goods. These data might depend on particular producer of machinery and other production means. It should depend on technical development of the country, in which the producer is located. Also, quality of produced goods (machines, etc) has important meaning. The embodied energy of particular objects might also depend on the time, when the production was done, because the improvement of production technology can change energy consumption needed for production of the same object when new tools and new technologies are applied.

Consequently, the investigation of the effects of embodied energy is practically continuous process, in which the obtained data might differ substantially.

Considering that biofuel production is a multistep technological task, and each step causes a decrease of energetic effectiveness, it is important to study the effects, and use all possible opportunities to increase the global energetic effectiveness of the whole production system.
The research has been performed under the financial support from the grant No. MB/WZ/4/2016 financed by the Polish Ministry of Science and Higher Education from the funds dedicated to science.

\section{References}

1. J.P. Soto Veiga, T.L. Romanelli, L.M. Gimenez, P. Busato, M. Milan, Scientia Agricola, 72, 471-477 (2015)

2. J.A. Mathews, Biofuels, Bioproducts and Biorefining, 3, 613-632 (2009)

3. J.P. Painuly, H. Rao, J. Parikh, Energy, 20, 219-233 (1995)

4. T. Juliszewski, T. Zając, Rapeseed Biofuels, (Governemental Agricultural and Forestry Publishing House) 49-51 (2007)

5. Z. Jasińska, A. Kotecki, Detailed Tillage of Plants, (Agricultural Academy) 412- 434 (1999)

6. G. Fontaras, V. Skoulou, G. Zanakis, A. Zabaniotou, Z. Samaras, Renewable Energy, 43, 201-209 (2012)

7. H.M. Chum, R.P. Overend, Fuel Processing Technology, 71, 187-195 (2001)

8. B. Cogan, Systems engineering - practice and theory, (Intech) (2012)

9. M. Börjesson, E.O. Ahlgren, R. Lundmark, D. Athanassiadis, Transportation Research Part D: Transport and Environment, 32, 239-252 (2014)

10. K. Shabestary, E.P. Hudson, Metabolic Engineering Communications, 3, 216-226 (2016)

11. T. Prodanuks, I. Veidenbergs, G. Cimdina, S. Mohannad, D. Blumberga, Energy Procedia, 95, 366-371 (2016)

12. J. Kuesters, J. Lammel, European Journal of Agronomy, 11, 35-43 (1999)

13. W.F. Pickard, Proceedings of the IEEE, 102, 11181122 (2014)

14. P. Moriarty, D. Honnery, Energy Policy, 93, 3-7 (2016)

15. D.J. Murphy, C.A. Hall, Ann. N.Y. Acad. Sci, 1185, 102-118 (2010)

16. H.T. Odum, Environment, power, and society for the twenty-first century. The hierarchy of energy, (2007)

17. M.T. Brown, R.A. Herendeen, Ecological Economics, 19, 219-235 (1996)

18. D. Weißbach, G. Ruprecht, A. Huke, K. Czerski, S. Gottlieb, Energy, 52, 2010-221 (2013)

19. A. Wasiak, O. Orynycz, ITM Web of Conferences, 15, 1-4 (2017)

20. P.I.I. Börjesson, Biomass and Bioenergy, 11, 305318 (1996)

21. E. Aguilera, G.I. Guzmán, J. Infante-Amate, M.G. de Molina, Embodied energy in agricultural inputs. Incorporating a historical perspective (SEHA) 1123 (2015) 